\title{
The cost of infant feeding in Liverpool, England
}

\author{
K Berridge* , AF Hackett, J Abayomi and SM Maxwell \\ School of the Outdoors, Leisure \& Food, Liverpool John Moores University, Barkhill Road, Liverpool L17 6BD, UK
}

Submitted 12 June 2003: Accepted 15 June 2004

\begin{abstract}
Objective: To investigate feeding practices in infants under the age of 4 months in Liverpool, England with particular reference to the cost of infant feeding.

Design: A cross-sectional survey consisting of self-completion questionnaires and interviews.

Setting: Subjects' homes within Central and South Liverpool Primary Care Trust areas. Subjects: One hundred and forty-nine women (aged 18 to 43 years) and their infants (mean age 13 weeks).

Results: The average weekly cost of breast-feeding was 11.58 compared with £9.60 for formula-feeding. Many breast- and formula-feeding women spent money however on items that were not needed or used only once or twice. This was especially true of first-time mothers. Characteristics significantly associated with higher spending were: feeding method - mothers that had or were partially breastfeeding $(P=0.001)$, education - those educated to degree level $(P=0.028)$, socioeconomic status - those in social classes I and II $(P=0.002)$ and age - those aged 30 years and over $(P=0.003)$.

Conclusions: This study demonstrates that while breast-feeding is often promoted as being free, this is not the case. Better information needs to be given to parents to avoid wasting money on items that are unnecessary, or where cheaper alternatives are available.
\end{abstract}

Extensive research has shown that breast milk is the best form of nutrition for infants, and is sufficient for at least the first 6 months of life ${ }^{1}$. Numerous studies have reported that breast-fed infants have decreased incidence of otitis media $^{2,3}$, diarrhoea ${ }^{4,5}$, respiratory infections ${ }^{6,7}$, urinary tract infections ${ }^{8}$, sudden infant death syndrome 9 , insulindependent diabetes ${ }^{10}$ and allergic diseases ${ }^{11}$, and may also have enhanced cognitive development ${ }^{12}$. Breast-feeding has also been shown to benefit maternal health by decreasing the frequency of premenopausal breast cancer $^{13,14}$, ovarian cancer ${ }^{15}$ and endometrial cancer ${ }^{16}$.

Despite the numerous beneficial health effects, the incidence and duration of breast-feeding in the UK have been low and static - 69\% of mothers initiate breastfeeding, but this drops to $42 \%$ by 6 weeks postpartum and to only $21 \%$ by 6 months ${ }^{17}$. The lowest rates of breastfeeding are seen amongst mothers who fall into the lowest socio-economic groups, and the impact of this on future health is probably substantial.

An obvious difference in cost between feeding methods might affect a family's selection of feeding method, but very little research has been carried out on the economic implications of breast-feeding. Those studies that have looked at the economics tend to concentrate on savings to the health-care system of not treating illnesses in formulafed babies. In 1995, the Department of Health in the UK estimated that $£ 35$ million per year was spent on treating gastroenteritis in formula-fed babies and that, for each $1 \%$ increase in the breast-feeding rate at 13 weeks, a saving of $\$ 500000$ in the treatment of gastroenteritis would be achieved $^{18}$. Considerations of the relative costs of formulaversus breast-feeding should also take into account the economic consequences of women working outside the home and the cost of producing, processing, packaging, transporting and storing formula from resources within the country or importing it from overseas. For example, it has been calculated that to supply cow's milk formula for all women with young babies in India would require the immediate development of an additional herd of 0.6 million lactating cows, needing 75000 acres of land for grazing, and would cost more than Rs 5 billion for daily maintenance (approximately $£ 67.5$ million) ${ }^{19}$.

Jelliffe and Jelliffe ${ }^{20}$ believe that human milk has economic significance on three different overlapping levels: the large scale (national or community level), the family level and the commercial level. According to Almroth et $a l .{ }^{21}$, breast milk can in many respects be regarded like any other food commodity, i.e. in terms of the benefits it brings versus the costs it incurs. They state that breast milk comes 'ready-to-feed' and the equipment needed for its delivery is supplied free. Therefore, the only cost of breast-feeding is the additional food the mother has 
to eat to produce the milk. The cost of formula-feeding includes not only the cost of formula, but also the costs of the equipment and fuel needed. Indeed, the few studies that have looked at the cost of infant feeding have taken this approach. Ball and Bennett ${ }^{22}$ estimate that the cost of purchasing formula may be almost twice the cost of the additional food intake required by breast-feeding women, amounting to a net cost of $\$ 885$ during the first year of infant life. Most studies relate to developing countries; only one estimate of the cost of formula-feeding appears to have been made in the UK, by the Joint Breast Feeding Initiative - $\$ 350$ per annum ${ }^{23}$. Furthermore, the studies that do exist seem to be quite crude in approach since they do not add in all the indirect costs, some of which may not be obvious, and rely heavily on assumptions, giving hypothetical cost savings. In a study in Honolulu ${ }^{24}$, the cost of infant formula and the cost of food a mother would consume to produce milk were calculated for the first 62 days of an infant's life. From the assumptions made, it was calculated that it cost at least an extra $\$ 45$ to $\$ 70$ to feed a newborn formula rather than to breast-feed them. These figures did not take into account feeding accessories such as bottles, teats, sterilisers, breast pumps, etc., and so the true cost is likely to be much higher.

These studies highlight the lack of accurate information available to health workers and parents regarding the cost of infant feeding. The aim of the present study was therefore to investigate these costs.

\section{Method}

For the purpose of this study, exclusive breast-feeding (EBF) is defined as never having been given any formula, partial breast-feeding (PBF) as being given some breast feeds and some formula feeds, and formula-feeding (FF) as never having been breast-fed.

Permission for the study was granted from Liverpool John Moores University Ethics Committee, Liverpool Women's Hospital Research and Development Committee, and Liverpool Research Ethics Committee.

Women were recruited from Liverpool Women's Hospital (LWH), and invited to take part by letter once their baby was born. They were asked to return a form in a pre-paid envelope stating whether they wanted to take part or not. If they wanted to take part, they were then contacted by phone to arrange a suitable time for an interview to take place (usually in their own home) when their baby was between 12 and 16 weeks old. These age parameters were chosen as by 12 weeks the method of infant feeding would have been well established, but after 16 weeks many women would be returning to work and therefore not available. This is also the minimum age at which weaning onto solids is recommended, and so infant feeding patterns would be changing, and this would affect the results. At the interview, written informed consent was obtained. Women were excluded from the study if their baby was premature or had congenital abnormalities that may have affected feeding. Due to time and travel constraints, women were not invited to take part if they lived outside a specific geographical area surrounding the hospital (i.e. outside Liverpool Central and South Primary Care Trust areas).

To determine all of the costs involved in feeding a baby, an interview proforma was devised to ask mothers about items they had purchased or were given as gifts for feeding their baby. This was based on the results of a pilot study ${ }^{25}$. Product information and prices were noted from retail outlets, including Boots, Mothercare, John Lewis, Babies ' $\mathrm{R}$ ' Us, local pharmacy chains and all the major supermarkets (prices were noted during January 2002 and rechecked in January 2003; no price increases were apparent during this time). Everything purchased up to the date of the interview was recorded, including items purchased before the birth. The average cost per week was calculated by dividing the total cost by the age of the infant.

The software package SPSS version 10 (SPSS Inc., Chicago, IL, USA) was used for all statistical analyses. Frequencies were computed and the chi-square test used to determine whether there were any associations between different variables.

The cost of extra dietary intake for breast-feeding mothers was not taken into account in this study.

\section{Results}

A total of 149 women were interviewed, Table 1 shows their demographic characteristics. There were similarities in the mean age of mothers responding (31 years), compared with all mothers delivering at LWH (29 years), and ethnicity $-95 \%$ of respondents were white European compared with $90 \%$ of all mothers delivering at LWH being white European. Women practising EBF were significantly more likely not to smoke $(P=0.00)$, to be educated to degree level $(P=0.00)$, be married or living with a partner $(P=0.010)$, to have been breast-fed as a baby $(P=0.012)$, to belong to a higher social class $(P=0.00)$, to be older $(P=0.011)$ and to have only one child $(P=0.038)$.

\section{Exclusive breast-feeders}

Table 2 shows a summary of the amount of money spent by EBF women. 'Savings from before' were items that were purchased for feeding a previous child and were being used for feeding the current child. These items were costed at current retail prices. 'Savings from gifts' was the amount of money saved from items purchased by family or friends. The 'amount spent' was the figure that the parent(s) spent on items for feeding their baby. The addition of these three categories gives the 'total amount'; this was divided by the age of the baby to give the 'amount per week'. With the exception of two women, all EBF women purchased a minimum of one nursing bra (maximum of eight), with an average of 3.3 bras 
Table 1 Demographic characteristics of respondents

\begin{tabular}{|c|c|c|c|c|c|c|c|c|}
\hline & \multicolumn{2}{|c|}{ Total } & \multicolumn{2}{|c|}{$\begin{array}{c}\text { Exclusive } \\
\text { breast-feeding }\end{array}$} & \multicolumn{2}{|c|}{$\begin{array}{c}\text { Partial } \\
\text { breast-feeding }\end{array}$} & \multicolumn{2}{|c|}{ Formula-feeding } \\
\hline & $n$ & $\%$ & $n$ & $\%$ & $n$ & $\%$ & $n$ & $\%$ \\
\hline \multicolumn{9}{|l|}{ Age (years) } \\
\hline Under 30 & 45 & 30 & 5 & 14 & 19 & 30 & 21 & 44 \\
\hline 30 and over & 104 & 70 & 32 & 86 & 45 & 70 & 27 & 56 \\
\hline \multicolumn{9}{|l|}{ Education } \\
\hline None & 12 & 8 & 2 & 5 & 3 & 4 & 7 & 15 \\
\hline School & 57 & 38 & 5 & 13 & 26 & 41 & 26 & 54 \\
\hline Vocational & 24 & 16 & 8 & 22 & 9 & 14 & 7 & 15 \\
\hline Degree or above & 56 & 38 & 22 & 60 & 26 & 41 & 8 & 16 \\
\hline \multicolumn{9}{|c|}{ Socio-economic status } \\
\hline $\begin{array}{l}\text { High (social } \\
\text { classes I \& II) }\end{array}$ & 75 & 50 & 30 & 81 & 30 & 47 & 15 & 31 \\
\hline $\begin{array}{l}\text { Middle (social } \\
\text { classes III \& IV) }\end{array}$ & 37 & 25 & 6 & 16 & 13 & 20 & 18 & 38 \\
\hline $\begin{array}{l}\text { Low (social class } \\
\text { V \& not working) }\end{array}$ & 37 & 25 & 1 & 3 & 21 & 33 & 15 & 31 \\
\hline \multicolumn{9}{|l|}{ Ethnicity } \\
\hline White & 141 & 95 & 36 & 97 & 58 & 91 & 47 & 98 \\
\hline Black & 5 & 3 & 1 & 3 & 3 & 5 & 1 & 2 \\
\hline Asian & 2 & 1 & 0 & 0 & 2 & 3 & 0 & 0 \\
\hline Other & 1 & 1 & 0 & 0 & 1 & 1 & 0 & 0 \\
\hline \multicolumn{9}{|l|}{ Marital status } \\
\hline Single/separated & 22 & 15 & 0 & 0 & 14 & 22 & 8 & 17 \\
\hline $\begin{array}{l}\text { Married/living } \\
\text { together }\end{array}$ & 127 & 85 & 37 & 100 & 50 & 78 & 40 & 83 \\
\hline \multicolumn{9}{|l|}{ Number of children } \\
\hline 1 child & 73 & 49 & 22 & 60 & 34 & 53 & 17 & 35 \\
\hline$>1$ child & 76 & 51 & 15 & 40 & 30 & 47 & 31 & 65 \\
\hline \multicolumn{9}{|l|}{ Primary Care Trust } \\
\hline Central & 81 & 54 & 16 & 43 & 35 & 55 & 30 & 63 \\
\hline South & 68 & 46 & 21 & 57 & 29 & 45 & 18 & 37 \\
\hline
\end{tabular}

purchased. The cost of these varied from £14 to £26 each (depending on the retail outlet), with an average total cost of nursing bras of $£ 46.17$ per mother. The majority of mothers used breast pads; only one woman did not use them. The number of breast pads used varied from two to 16 per day. One woman had spent $£ 60.48$ on breast pads during the first 12 weeks of her baby's life, while the average amount spent on these items was 24.03 . One woman got a breast pad stuck in her washing machine and had to call the engineer out at an additional cost of $₫ 60.00$ (this was not included in the figures). Other items purchased by the breast-feeding mothers included breast pumps (only three of the women did not have a pump), breast-milk freezer bags, muslin cloths (for winding the baby), nipple shields, breast shells, breast and nipple creams/sprays, breast-milk storage bottles, sterilisers and support pillows. Many items were purchased before the baby was born, particularly by first-time mothers, and then were not needed or not used - $12(32 \%)$ EBF mothers spent money in this way (three-quarters of whom were first-time mothers). Other items purchased but not used were breast and nipple creams and sprays, breast shells and shields, and breast pumps. The average total amount of money spent needlessly by the 12 mothers was $£ 10.42$ per mother (£0.90 per week).

\section{Partial breast-feeders}

Table 3 shows the amount of money spent by PBF women. This group included women who had exclusively breastfed prior to being interviewed but had now stopped and were giving only formula milk $(n=43)$, and also women who were giving both breast and formula milk $(n=21)$ at the time of the interview. The costs were calculated as for the EBF women. PBF mothers purchased fewer nursing bras than the exclusive breast-feeders (mean 2.5 vs. 3.3); only $32.8 \%$ of PBF women were still breast-feeding and

Table 2 Costs for exclusive breast-feeding mothers

\begin{tabular}{|c|c|c|c|c|c|c|c|}
\hline & $n$ & $\begin{array}{l}\text { Mean age of } \\
\text { baby (weeks) }\end{array}$ & $\begin{array}{l}\text { Mean savings } \\
\text { from before }\end{array}$ & $\begin{array}{l}\text { Mean savings } \\
\text { from gifts }\end{array}$ & $\begin{array}{c}\text { Mean amount } \\
\text { spent }\end{array}$ & $\begin{array}{l}\text { Mean total } \\
\text { amount }\end{array}$ & $\begin{array}{l}\text { Mean amount } \\
\text { per week }\end{array}$ \\
\hline 1 child & 22 & 12.9 & $£ 0.00$ & $£ 18.09$ & $£ 144.72$ & $£ 162.82$ & $£ 12.89$ \\
\hline$>1$ child & 15 & 12.6 & $£ 29.55$ & $£ 11.50$ & $£ 78.64$ & $£ 119.68$ & $£ 9.66$ \\
\hline Total (mean) & 37 & 12.8 & $£ 11.98$ & $£ 15.42$ & $£ 117.93$ & $£ 145.33$ & $£ 11.58$ \\
\hline
\end{tabular}

Amount per week - range: £3.13-£23.15, standard deviation: £4.49. 
Table 3 Costs for partial breast-feeding mothers

\begin{tabular}{|c|c|c|c|c|c|c|c|}
\hline & $n$ & $\begin{array}{l}\text { Mean age of } \\
\text { baby (weeks) }\end{array}$ & $\begin{array}{l}\text { Mean savings } \\
\text { from before }\end{array}$ & $\begin{array}{l}\text { Mean savings } \\
\text { from gifts }\end{array}$ & $\begin{array}{c}\text { Mean amount } \\
\text { spent }\end{array}$ & $\begin{array}{l}\text { Mean total } \\
\text { amount }\end{array}$ & $\begin{array}{l}\text { Mean amount } \\
\text { per week }\end{array}$ \\
\hline 1 child & 34 & 13.3 & $£ 0.00$ & $£ 18.44$ & $£ 164.11$ & $£ 182.64$ & $£ 14.01$ \\
\hline$>1$ child & 30 & 13.8 & $£ 38.41$ & $£ 18.43$ & $£ 130.13$ & $£ 187.44$ & $£ 13.73$ \\
\hline Still breast-feeding & 21 & 13.4 & $£ 21.33$ & $£ 27.87$ & $£ 115.21$ & $£ 164.41$ & $£ 12.33$ \\
\hline No longer breast-feeding & 43 & 13.6 & $£ 16.38$ & $£ 13.84$ & $£ 164.29$ & $£ 194.89$ & $£ 14.63$ \\
\hline Total (mean) & 64 & 13.5 & $£ 18.00$ & $£ 18.44$ & $£ 148.18$ & $£ 184.89$ & $£ 13.87$ \\
\hline
\end{tabular}

Amount per week - range: £4.01-£27.24, standard deviation: £4.71.

Table 4 Costs for formula-feeding mothers

\begin{tabular}{|c|c|c|c|c|c|c|c|}
\hline & $n$ & $\begin{array}{l}\text { Mean age of } \\
\text { baby (weeks) }\end{array}$ & $\begin{array}{l}\text { Mean savings } \\
\text { from before }\end{array}$ & $\begin{array}{l}\text { Mean savings } \\
\text { from gifts }\end{array}$ & $\begin{array}{c}\text { Mean amount } \\
\text { spent }\end{array}$ & $\begin{array}{l}\text { Mean total } \\
\text { amount }\end{array}$ & $\begin{array}{l}\text { Mean amount } \\
\text { per week }\end{array}$ \\
\hline 1 child & 16 & 14.0 & $£ 0.00$ & $£ 15.93$ & $£ 104.74$ & $£ 120.66$ & $£ 8.71$ \\
\hline$>1$ child & 32 & 13.3 & $£ 15.40$ & $£ 7.25$ & $£ 110.28$ & $£ 132.93$ & $£ 10.04$ \\
\hline Free milk & 17 & 13.4 & $£ 3.53$ & $£ 5.76$ & $£ 60.87$ & $£ 70.15$ & $£ 5.27$ \\
\hline Pay for milk & 31 & 13.6 & $£ 13.96$ & $£ 12.54$ & $£ 134.52$ & $£ 161.02$ & $£ 11.97$ \\
\hline Total (mean) & 48 & 13.5 & $£ 10.27$ & $£ 10.14$ & $£ 108.43$ & $£ 128.84$ & $£ 9.60$ \\
\hline
\end{tabular}

Amount per week - range: $£ 2.43-£ 17.66$, standard deviation: £4.16.

$27 \%$ had ceased breast-feeding within the first week Seventeen per cent of all PBF women did not purchase any nursing bras, perhaps because they anticipated not breast-feeding for very long. All the women apart from two purchased branded goods. The most popular brand was Avent, with 75\% of mothers purchasing Avent feeding bottles and 58\% purchasing an Avent steriliser. Other popular brands were Maws, Mothercare and Boots own brands. Money was spent on items that were not used by $70 \%$ of all PBF mothers; of this $70 \%, 53 \%$ were first-time mothers. The average amount spent needlessly was $£ 17.59$ in total (£1.31 per week), mostly on breast pumps (31\% of mothers), breast and nipple creams and sprays (31\%) and bottle warmers (22\%).

\section{Formula-feeders}

Table 4 shows a summary of the amount of money spent by $\mathrm{FF}$ women. The costs were calculated as for the exclusive and partial breast-feeding women.

Items purchased by the FF women included bottles, teats, formula, sterilisers, bottle brushes, bottle carriers, bottle warmers and travel flasks. As with the PBF women, the majority of FF women purchased branded goods; $67 \%$ purchased Avent feeding bottles and 50\% purchased Avent sterilisers. Steam or microwave sterilisation was the most popular choice, with $90 \%$ of women choosing this method. The remaining $10 \%$ of women used cold-water sterilisation systems. On average, FF mothers purchased 10 feeding bottles (range 4-22), at an average cost of $£ 20.12$ per mother. Twenty-seven per cent of all FF women spent money on items that were either ineffective (e.g. plug-in bottle warmers that took too long to warm the bottle) or were not used (extra bottles and teats). The average amount spent needlessly was £15.19 during the first 4 months of the baby's life (£1.15 per week).
Table 5 shows a comparison of the infant feeding costs. PBF was the most expensive way to feed an infant. EBF was not free and was 13\% more expensive than FF.

\section{Predictors of high, medium or low spending}

The subjects were coded as high, medium or low spenders to discover which maternal characteristics were associated with higher spending.

The subjects were divided into tertiles according to the weekly amount spent. Fifty (33.6\%) were classed as low spenders (£0.00-£9.88), 49 (32.9\%) as medium spenders (£9.89-£13.42) and 50 (33.6\%) as high spenders (£13.43$£ 27.24)$.

Characteristics significantly associated with high spending were:

- Feeding method - mothers who had been or were partially breast-feeding ( $\left.\chi^{2}=19.11, P=0.001, \mathrm{df}=4\right)$;

- Education - those educated to degree level $\left(\chi^{2}=14.11, P=0.028, \mathrm{df}=6\right)$;

- Socio-economic status - those in social classes I and II $\left(\chi^{2}=16.54, P=0.002, \mathrm{df}=4\right)$;

- Age - those aged 30 years and over $\left(\chi^{2}=11.38\right.$, $P=0.003, \mathrm{df}=2$ ).

Table 5 Comparison of infant feeding costs

\begin{tabular}{lcccr}
\hline & $n$ & $\begin{array}{c}\text { Mean age } \\
\text { of baby } \\
\text { (weeks) }\end{array}$ & $\begin{array}{c}\text { Average } \\
\text { total } \\
\text { amount }\end{array}$ & $\begin{array}{r}\text { Average } \\
\text { weekly } \\
\text { amount }\end{array}$ \\
\hline Exclusive breast-feeding & 37 & 12.8 & $£ 145.33$ & $£ 11.58$ \\
Partial breast-feeding & 64 & 13.5 & $£ 184.89$ & $£ 13.87$ \\
Formula-feeding & 48 & 13.5 & $£ 128.84$ & $£ 9.60$ \\
\hline
\end{tabular}




\section{'High' and 'low' cost models}

High and low cost models for breast- and formula-feeding were then constructed. The high cost model was constructed by listing the maximum number of items purchased by subjects, then costing these using the most expensive brands at the most expensive outlets (Table 6). For the low cost model, the minimum number of items purchased by subjects was listed and then costed using the cheapest brands at the cheapest outlets (Table 7). The price of formula was included in the formula-feeding models. For the high cost formula-feeding model, the price of ready-to-feed formula was used as this is the most expensive way of formula-feeding, approximately 3.5 times more expensive than powdered formula; one of the FF mothers fed her infant this way. For the low cost breastfeeding model, the price of a breast pump was included as $92 \%$ of EBF mothers had a breast pump, and the price of sterilisation was included as $78 \%$ of these women had a steriliser. Arguably, neither is essential.

The high and low cost models can be summarised as follows:

$\begin{array}{lcc} & \text { High cost (per week) } & \text { Low cost (per week) } \\ \text { Breast-feeding } & £ 34.60 & £ 2.40 \\ \text { Formula-feeding } & £ 31.43 & £ 6.30\end{array}$

There was little difference between the cost of breast- and formula-feeding estimated by the high cost model, with formula-feeding estimated at $10 \%$ less than breast-feeding (similar to the difference of $13 \%$ between these two feeding methods observed from the interviews above).
There was a greater difference between the cost of breastand formula-feeding when using the low cost model though, with breast-feeding 62\% cheaper than formulafeeding. This difference would be reduced if the mother received milk tokens; the formula-feeding cost would only be 73 p per week rather than $£ 6.30$.

\section{Discussion}

The sample size for this study was relatively small and may not be representative of infant feeding practices overall. However, women from a wide variety of backgrounds took part (although not from ethnic minority groups) and a wide range of practices was observed. Thus a variety of issues were highlighted. Breast-feeding is frequently promoted as being free, but the most striking feature of this study is that it was cheaper to formula-feed than to breast-feed. This is of particular importance to women on low incomes who may try breast-feeding because they have been told it is free, only to discover this is not the case. This finding supports media portrayals that breast-feeding is a lifestyle choice, primarily for the middle classes.

It was surprising to discover the full extent of goods marketed to both breast- and formula-feeding women. This may not be surprising considering that 670000 babies were expected to be born in the UK in 2003, and so the potential for companies to profit is huge. According to $\mathrm{Mintel}^{26}$, the infant feeding and hygiene market was valued at $\$ 50$ million in 2001, and the baby milk market was estimated at $£ 175.8$ million in $2002^{27}$. The range of products marketed to breast-feeding women alone included nursing bras, sleep

Table 6 High cost model

\begin{tabular}{llr}
\hline Item and number & Retail source & Cost \\
\hline Breast-feeding & & \\
Nursing bras $\times 8$ & (John Lewis own) & $£ 208.00$ \\
Night-shirts $\times 4$ & (Blooming Marvellous) & $£ 79.96$ \\
Breast pads $\times 896$ & (Avent 30s - Toys R Us) & $£ 119.17$ \\
Antiseptic nipple spray & (Boots own) & $£ 2.15$ \\
Breast cream & (Kamillosan - Boots) \\
Breast shells & (Avent - John Lewis) & $£ 4.95$ \\
Nipple shields & (Avent - John Lewis) & $£ 9.99$ \\
Breast pump & (Medela - Boots) & $£ 4.50$ \\
Breast-milk storage bottles $\times 8$ & (Avent - Boots) & $£ 39.95$ \\
Breast-milk freezer bags $\times 40$ & (Boots own) & $£ 17.98$ \\
Steriliser & (Avent - Asda) & $£ 6.99$ \\
Support pillow & (Mothercare own) & $£ 39.99$ \\
Total amount & & $£ 19.99$ \\
Total per week (16) & & $£ 553.62$ \\
Formula-feeding & $£ 34.60$ \\
Bottles $\times$ 20 & & \\
Teats $\times$ 20 & & $£ 63.00$ \\
Steam steriliser & (Avent - Boots) & $£ 22.90$ \\
Formula & (Avent - Boots) & $£ 39.99$ \\
Bottle warmer & (Avent - Asda) & $£ 329.28$ \\
Bottle carrier & (C + G Premium RTF) \\
Powder dispenser & (Lindam Night \& Day system - Mothercare) \\
Bottle/teat brushes & (Avent - Boots) & $£ 9.99$ \\
Total amount & (Avent - Boots) & $£ 3.99$ \\
Total per week (16) & (Boots own) & $£ 3.75$ \\
& & $£ 31.43$ \\
& &
\end{tabular}


Table 7 Low cost model

\begin{tabular}{|c|c|c|}
\hline Item and number & Retail source & Cost \\
\hline \multicolumn{3}{|l|}{ Breast-feeding } \\
\hline Bras $\times 1$ & (No brand - department store) & $£ 7.00$ \\
\hline Breast pads $\times 224$ & (Asda own brand 30s) & $£ 10.08$ \\
\hline Breast pump & (Boots own brand) & $£ 15.99$ \\
\hline \multicolumn{3}{|c|}{ Cold-water sterilisation } \\
\hline Tongs & (Mothercare own) & $£ 0.99$ \\
\hline Bowl & (Pound shop) & $£ 1.00$ \\
\hline Steri tabs & (Asda own) & $£ 3.32$ \\
\hline Total amount & & $£ 38.38$ \\
\hline Total per week (16) & & $£ 2.40$ \\
\hline \multicolumn{3}{|l|}{ Formula-feeding } \\
\hline Bottles $\times 6$ & (No brand - Ethel Austens) & $£ 4.50$ \\
\hline Teats $\times 6$ & (Asda own brand) & $£ 1.88$ \\
\hline \multicolumn{3}{|c|}{ Cold-water sterilisation } \\
\hline Tongs & (Mothercare own) & $£ 0.99$ \\
\hline Bowl & (Pound shop) & $£ 1.00$ \\
\hline Steri tabs & (Asda own) & $£ 3.32$ \\
\hline Formula & $(\mathrm{C}+\mathrm{G}$ Premium Powdered) & $£ 89.12$ \\
\hline Total amount & & $£ 100.81$ \\
\hline Total per week (16) & & $£ 6.30$ \\
\hline
\end{tabular}

bras, nursing night-shirts, inflatable support pillows, breast pads (disposable and washable), breast shells, nipple shields, nipple and breast creams and sprays, breast pumps (manual, battery or electrically operated), breast pump bottles, breast-milk freezer bags, breast-milk storage kits, back-to-work breast-feeding kits and soothing breast gel packs. Information was misleading; for example, on a pack of nursing bras manufactured by a company called EmmaJane was a quote from the Royal College of Midwives stating that 'breast-feeding is free' - as long as you ignore the $£ 18$ to purchase that bra! It is debatable whether all the items purchased for breast-feeding were truly essential, and it is suggested that breast-feeding has become unnecessarily commercialised.

Many of the mothers (especially first-time mothers) purchased items before they had the baby, 'just in case' they needed them - in many cases they did not, or if they did, used them only once or twice. Typical of such items were breast creams, plug-in bottle warmers and more bottles and teats than needed. The amount of money 'wasted' on these items may be due to ignorance of what is required and so increased information, particularly for first-time mothers, may help to reduce the cost of infant feeding. This would particularly benefit mothers with little disposable income available.

Alternatively, the amount of money spent on these items may be a result of the consumerist age in which we live. Everyday life in the developed world appears to be dominated by our relationship with consumer goods ${ }^{28}$, and they play a potentially important role in who we are and how we construct our social lives. Thus to display to the outside world that they are good parents, first-time parents may feel they need to have all the gadgets/equipment available. Increasingly, people are moving away from their place of origin and may not have the support and advice of family members at hand to help them with a new baby, so confidence in parenting skills may come from the purchase of consumer goods instead. The majority of women in this study (95\%) were white European. It would be interesting to see if women belonging to ethnic minorities purchased infant feeding goods to the same extent. Of the eight women in this study who were not white European, only two (25\%) were high spenders.

\section{Working mothers}

Seventy-one per cent of all mothers in this study had either already returned to work or were currently on maternity leave, and many items were purchased by these women in anticipation of return to work. This was particularly true of breast pumps and breast-milk storage bottles/freezer bags. Returning to work inevitably creates difficulties for breastfeeding, and despite the advocacy of bodies such as the National Childbirth Trust for expressing breast milk for feeding later, it is likely that most babies are switched to formula-feeding. Seventy per cent of women who were still breast-feeding (either exclusively or partially) were on maternity leave and trying to get their baby to take a bottle in preparation for leaving them with a child-minder or at nursery. This was a cause of anxiety for many of these women and was the main reason for early cessation of breast-feeding.

\section{Convenience}

Modern working mothers require equipment that helps them and so products that save time were popular with parents happy to pay for the added convenience they offer, i.e. microwave sterilisers and disposable single-use products. Breast pads, for example, are available either as washable re-usuables or as disposables; but in this study, only seven women used washable pads ( $7 \%$ of all breastfeeding women). A worrying consequence of the increasing use of such disposable items is the environmental impact of their disposal.

\section{Low-income parents}

In this study, 17 of the FF women (35\%) received free milk. Currently under the Welfare Food Scheme, parents in receipt of income support or income-based job seekers' allowance ( $₫ 30.95-£ 51.40$ per week for a lone parent or $£ 61.35$ - 80.65 per week for a couple) are entitled to tokens which can be exchanged for one 900-g tin of powdered infant formula per week (this would cost between $£ 5.57$ and $\$ 6.09$ to purchase) or 7 pints of liquid milk per week for the mother (costing approximately $£ 2.20)^{29}$. This represents a greater cost saving for FF women, and therefore offers no material incentive for breast-feeding. At the time of writing, the Welfare Food Scheme was being reviewed to include a greater material incentive for those on low incomes to breast-feed, possibly in the form of vouchers to be exchanged for 'healthy foods'.

The 1997/8 Family Expenditure Survey showed that the $20 \%$ of single parent households with the lowest income 
spent $£ 28.20$ per week on food ${ }^{30}$. The weekly retail cost of $900 \mathrm{~g}$ of infant formula averages $£ 6.23$; thus if they had to pay for formula, it would account for $22 \%$ of their food expenditure.

\section{Extra energy intake for lactating women}

Extra energy intake for lactating women was not taken into account in this study. The Department of Health ${ }^{31}$ recommends an extra $450 \mathrm{kcal} \mathrm{day}^{-1}$ for lactating women. However, a number of studies looking at energy balance in lactating women both in developed and developing countries have shown that women are highly variable in the way they meet the energy cost of lactation (through mobilisation of fat stores, decrease in energy expenditure, increase in dietary intake or a combination of all three), and that lactation can be sustained on intakes similar to those in the non-pregnant, non-lactating state ${ }^{32-34}$.

\section{Conclusion}

Breast-feeding was not 'free' and should not be promoted in this way, especially to women on low incomes. This study demonstrates the need for the advice given to parents to be based on objective evidence rather than beliefs or commercial information. Better information needs to be available for women, particularly first-time mothers, about items that are necessary, useful or likely to be considered a waste of money. The high and low cost models suggest that it is possible for large cost savings to be made, simply by buying non-branded goods at discount-style shops. The low cost model for breastfeeding shows that it can be cheaper than formulafeeding, although it should never be described as being free. Midwives and health visitors could use these models to advise women, enabling them to make informed choices about any infant feeding products they purchase and avoid wasting money on unnecessary or ineffective products.

Greater financial incentives for breast-feeding could be adopted by the UK government, e.g. removing VAT on commonly used breast-feeding items such as nursing bras, breast pads and breast pumps. Despite the existence of population-based dietary guidelines that recommend EBF for between 4 and 6 months $^{35}$, policies such as early discharge from maternity wards and legislation on maternity leave hinder these targets being achieved. By developing a 'breast-feeding culture' as advocated by the Innocenti Declaration $^{36}$, where breast-feeding is seen as the normal method of infant feeding, more women may feel able to breast-feed with confidence. It is clear that further research is needed in this area, particularly focusing on women from ethnic minority backgrounds to ascertain their infant feeding purchase behaviour. Large-scale studies are needed both in the UK and elsewhere to direct government policies that can promote, protect and support all breast-feeding women regardless of their nationality, economic circumstances, educational level or age.

\section{References}

1 World Health Organization. The optimal duration of exclusive breast-feeding: results of a WHO systematic review. Indian Pediatrics 2001; 38: 565-7.

2 Ball TM, Wright AL. Health care costs of formula-feeding in the first year of life. Pediatrics 1999; 103: 870-6.

3 Owen MJ, Baldwin CD, Swank PR, Pannu AK, Johnson DL, Howie VM. Relation of infant feeding practices, cigarette smoke exposure, and group child care to the onset and duration of otitis media with effusion in the first two years of life. Journal of Pediatrics 1993; 123: 702-11.

4 Dewey KG, Heinig MJ, Nommsen-Rivers LA. Differences in morbidity between breast-fed and formula-fed infants. Journal of Pediatrics 1995; 126: 696-702.

5 Froozani MD, Permehzadah K, Dorosty Motlagh AR, Golestan B. Effect of breast-feeding education on the feeding pattern and health of infants in their first four months in the Islamic Republic of Iran. Bulletin of the World Health Organization 1999; 77: 381-5.

6 Wright AL, Holberg CJ, Taussig LM, Martinez FD. Relationship of infant feeding to recurrent wheezing at age 6 years. Archives of Pediatrics \& Adolescent Medicine 1995; 149: 758-63.

7 Cushing RG, Samet JM, Lambert WE, Skipper BJ, Hunt WC, Young SA, et al. Breastfeeding reduces risk of respiratory illness in infants. American Journal of Epidemiology 1998; 147: 863-70.

8 Pisacane A, Graziano L, Mazzarella G, Scarpellino B, Zona G. Breast-feeding and urinary tract infection. Journal of Pediatrics 1992; 120: 87-9.

9 Ford RPK, Taylor BJ, Mitchell EA, Enright SA, Stewart AW, Becroft DMO, et al. Breast-feeding and the risk of sudden infant death syndrome. International Journal of Epidemiology 1993; 22: 885-90.

10 Pettitt DJ, Forman MJ, Hanson RL, Knowler WC, Bennett PH. Breast-feeding and incidence of non-insulin-dependent diabetes mellitus in Pima Indians. Lancet 1997; 350: 166-8.

11 Chandra RK. Five year follow-up of high-risk infants with family history of allergy exclusively breast-fed or fed partial whey hydrolysate, soy and conventional cow's milk formula. Nutrition Research 1998; 18: 1395-411.

12 Anderson JW, Johnstone BM, Remley DT. Breast-feeding and cognitive development: a meta analysis. American Journal of Clinical Nutrition 1999; 70: 525-35.

13 Newcomb PA, Storer BE, Longnecker MP, Mittendorf R, Greenberg ER, Clapp RW, et al. Lactation and a reduced risk of pre-menopausal breast cancer. New England Journal of Medicine 1994; 330: 81-7.

14 Zheng T, Holford TR, Mayne ST, Owens PH, Zhang Y, Zhang $\mathrm{B}$, et al. Lactation and breast cancer risk: a case-control study in Connecticut. British Journal of Cancer 2001; 84: 1472-6.

15 Rosenblatt KA, Thomas DB. Lactation and the risk of epithelial ovarian cancer. The WHO Collaborative Study of Neoplasia and Steroid Contraceptives. International Journal of Epidemiology 1993; 22: 192-7.

16 Rosenblatt KA, Thomas DB. Prolonged lactation and endometrial cancer. International Journal of Epidemiology 1995; 24: 499-503.

17 Hamlyn B, Brooker S, Oleinikova K, Wands S. Infant Feeding 2000. London: The Stationery Office, 2002.

18 Department of Health. Breastfeeding: Good Practice Guidance to the NHS. London: Her Majesty's Stationery Office, 1995. 
19 Gupta A, Khanna K. Economic value of breast-feeding in India. National Medical Journal of India 1999; 12: 123-7.

20 Jelliffe DB, Jelliffe EFP. Human Milk in the Modern World. Oxford: Oxford University Press, 1978.

21 Almroth S, Greiner T, Latham MC. Economic importance of breastfeeding. Food and Nutrition 1979; 5: 4-10.

22 Ball TM, Bennett DM. The economic impact of breastfeeding. Pediatric Clinics of North America 2001; 48: 253-62.

23 Inch S. The importance of breastfeeding. In: Butriss J, ed. The Growing Cycle. London: National Dairy Council, 1994; $27-42$.

24 Jarosz LA. Breast-feeding versus formula: cost comparison. Hawaii Medical Journal 1993; 52: 14-8.

25 Berridge K, Hackett AF, Abayomi J, Maxwell SM. An investigation into the relative costs of breast- and bottlefeeding in Liverpool infants up to the age of four months. Proceedings of the Nutrition Society 2001; 60: 212A.

26 Mintel. Baby Food and Drink, Market Intelligence - UK Report. London: Mintel, 2002.

27 Mintel. Nursery Equipment, Market Intelligence - UK Report. London: Mintel, 2002.

28 Miles S. Consumerism - as a Way of Life. London: Sage, 1998.

29 Department of Health. Scientific Review of the Welfare Food Scheme. London: The Stationery Office, 2002.

30 Office of National Statistics. Family Spending; A Report of the
1997-98 Family Expenditure Survey. London: The Stationery Office, 1998.

31 Department of Health. Dietary Reference Values for Food Energy and Nutrients for the United Kingdom. London: Her Majesty's Stationery Office, 1991.

32 Butte NF, Garza C, Stuff JE, O'Brian Smith E, Nichols BL Effect of maternal diet and body composition on lactational performance. American Journal of Clinical Nutrition 1984; 39: 296-306.

33 Chou T, Chan GM, Moyer-Mileur L. Postpartum body composition changes in lactating and non-lactating primiparas. Nutrition 1999; 15: 481-4.

34 Lovelady C, Garner KE, Moreno KL, Williams JP. The effect of weight loss in overweight, lactating women on the growth of their infants. New England Journal of Medicine 2000; 342 . $449-53$.

35 Project participants. Nutrition and diet for healthy lifestyles in Europe: science and policy implications [Eurodiet core report]. In: Kafatos AG, Codrington CA, eds. Eurodiet Reports and Proceedings [special isssue]. Public Health Nutrition 2001; 4(2A): 265-73.

36 World Health Organization (WHO)/United Nations Children's Fund (UNICEF). The Innocenti Declaration on the Protection, Promotion and Support of Breastfeeding. Geneva: WHO/UNICEF, 1990. 